IZA DP No. 9031

Does Commuting Affect Health?

Annemarie Künn-Nelen

April 2015

Forschungsinstitut zur Zukunft der Arbeit Institute for the Study of Labor 


\title{
Does Commuting Affect Health?
}

\author{
Annemarie Künn-Nelen \\ ROA, Maastricht University \\ and IZA
}

\section{Discussion Paper No. 9031 \\ April 2015}

\author{
IZA
}
P.O. Box 7240
53072 Bonn
Germany

Phone: +49-228-3894-0

Fax: +49-228-3894-180

E-mail: iza@iza.org

Any opinions expressed here are those of the author(s) and not those of IZA. Research published in this series may include views on policy, but the institute itself takes no institutional policy positions. The IZA research network is committed to the IZA Guiding Principles of Research Integrity.

The Institute for the Study of Labor (IZA) in Bonn is a local and virtual international research center and a place of communication between science, politics and business. IZA is an independent nonprofit organization supported by Deutsche Post Foundation. The center is associated with the University of Bonn and offers a stimulating research environment through its international network, workshops and conferences, data service, project support, research visits and doctoral program. IZA engages in (i) original and internationally competitive research in all fields of labor economics, (ii) development of policy concepts, and (iii) dissemination of research results and concepts to the interested public.

IZA Discussion Papers often represent preliminary work and are circulated to encourage discussion. Citation of such a paper should account for its provisional character. A revised version may be available directly from the author. 
IZA Discussion Paper No. 9031

April 2015

\section{ABSTRACT}

\section{Does Commuting Affect Health?*}

This paper analyzes the relation between commuting time and health in the United Kingdom. I focus on four different types of health outcomes: subjective health measures, objective health measures, health behavior, and health care utilization. Fixed effect models are estimated with British Household Panel Survey data. I find that whereas objective health and health behavior are barely affected by commuting time, subjective health measures are clearly lower for people who commute longer. A longer commuting time is, moreover, related to more visits to the general practitioner. Effects turn out to be more pronounced for women and for commuters driving a car. For women, commuting time is also negatively related to regular exercise and positively to calling in sick.

JEL Classification: I12, R41

Keywords: health, commuting time, transportation mode

Corresponding author:

Annemarie Künn-Nelen

ROA, Maastricht University

P.O. Box 616

6200 MD Maastricht

The Netherlands

E-mail: a.kuenn@maastrichtuniversity.nl

\footnotetext{
* Part of this paper was written during my stay at the University of Wuppertal. I thank Eric Bonsang, Didier Fouarge, Hendrik Jürges, and participants of the 2011 ESPE conference for suggestions and comments on earlier versions of this paper.
} 


\section{Introduction}

In this paper, I analyze the relation between commuting and health. As can be seen in Figure 1, commuting plays a big role in the everyday life of the European working population. Even in Austria, which has the lowest average commuting time among the European countries participating in the European Working Conditions Survey, the average daily time spent on commuting exceeds 30 minutes. The Dutch spend the most time commuting, more than 45 minutes per day, on average. In the United Kingdom, the average commuting time is 43 minutes.

[Figure 1 around here]

Commuting time has increased over time. Among other reasons, this could be due to the increase in fixed-term contracts (Labour Force Survey 2000-2013) as individuals are not likely to move with every job change. Since most European labor markets are becoming increasingly flexible, the percentage of people who need to commute and the amount of time commuting can be expected to increase even further. Since the literature has found that commuting is often related to higher levels of fatigue (Lyons and Chatterjee 2008) and objective and subjective levels of stress (Gottholmseder et al. 2009; Wener et al. 2003; White and Rotton 1998), commuting is expected to negatively affect health.

This paper aims to analyze the relation between commuting time and health. I focus on passive commuters, that is, those commuting by car, motorcycle/moped, or public transportation ${ }^{1}$ First, I analyze whether commuting time affects specific health outcomes. Four types of health are analyzed: subjective health (e.g., health satisfaction), objective health (e.g., health problems), health utilization (e.g., the number of doctor visits), and health behavior (e.g., regular exercise). Second, I analyze whether the relation between commuting time and health is heterogeneous across commuting modes and gender.

\footnotetext{
${ }^{1}$ The distinction between active and passive commuting is important in the context of health consequences (e.g., Hansson et al. 2011). This distinction should not be confused with differentiation across commuting types with active and passive control, as adopted, for example, by Roberts et al. (2011).
} 
This paper uses data from the British Household Panel Survey (BHPS) to analyze the relation between commuting time and several measures of health. The BHPS has the advantage of including a large range of individual characteristics over many years. It includes detailed information on commuting from 1991 to 2008. Most of the health measures are available the whole panel length as well. Due to the panel structure of the data set, fixed effect (FE) analyses in which time-invariant idiosyncratic effects are controlled for are possible.

This paper thereby contributes to the literature by estimating an FE model controlling for unobserved time-invariant heterogeneity to show the effect of commuting time on four types of health outcomes: subjective health, objective health, health behavior, and health care utilization. Additional data from the UK household longitudinal study Understanding Society enable me to explore whether the relation I find between commuting time and health can be explained by differences in nutrition, physical activity, and sleep quality.

I find that whereas objective health and health behavior are barely affected by commuting time, subjective health measures are clearly lower for people who commute longer. I find that longer commuting time is related to lower health satisfaction and to a lower health status. Those who commute longer also visit the general practitioner more often. These findings turn out to be robust against several specifications and subsamples. Differentiation of the health effects of commuting across transportation mode and gender shows that adverse health effects are more pronounced for women and for those commuting by car. Sleep quality and physical activity could explain the more pronounced negative health effects for women and car drivers.

The structure of this paper is as follows: The next section reviews the related literature. Section 3 describes the data and provides sample statistics. Section 4 explains the empirical strategy. Section 5 reports the results, including several robustness checks, and also discusses explanations for the findings. Section 6 concludes the study.

\section{$2 \quad$ Literature and expected relations}

An extensive literature analyzes the (cross-sectional) relation between commuting and health. It is important to distinguish between passive and active commuting types (e.g., 
Hansson et al. 2011; Lindstrom 2008; Gatersleben and Uzzell 2007). Active commuting, such as commuting by bicycle or walking, is related to increased physical activity and lower probabilities of obesity (Lindström 2008). Moreover, active commuting is reported to be more relaxing and exciting than commuting by car or public transportation (Gatersleben and Uzzell 2007). These passive commuting modes are perceived as more stressful and boring (Gatersleben and Uzzell 2007). Since these different commuting types could have opposing effects on health, including both passive and active commuting types could result in their effects being canceled out.

The literature provides several channels through which (passive) commuting could affect different types of health measures. Both fatigue and chronic stress symptoms can induce cardiovascular abnormalities and dysfunction related to the onset of heart disease (Lyons and Chatterjee 2008). Therefore, many studies address the relation between commuting, on the one hand, and fatigue and (objective and subjective measures of) stress, on the other hand. Lyons and Chatterjee (2008) review the literature that analyzes possible mechanisms. For example, they mention several studies showing that longer commuting time is related to fatigue symptoms (e.g., Kageyama et al. 1998), less nocturnal sleep (e.g., Walsleben et al. 1999), and reduced sleep time (e.g., Costal et al. 1988). Moreover, several studies showed that commuting is related to self-perceived stress (e.g., Gottholmseder et al. 2009; Wener et al. 2003; Hennessy and Wiesenthal 1999; Schaeffer et al. 1988). There is also literature showing a clear relation between commuting and objective measures of (cardiovascular) stress. White and Rotton (1998), for example, showed that commuting is associated with increased pulse rate and systolic blood pressure. Koslowsky et al. (1995) showed that commuting strain is not only associated with raised blood pressure, but also with, for example, musculoskeletal disorders and increased anxiety.

Based on the abovementioned studies, commuting time is expected to negatively affect health. Studies focusing on passive commuting types have found that long commuting times are related to higher absenteeism (Kluger 1998; Costal et al. 1988). More recently, van Ommeren and Gutiérrez-i Puigarnau (2011) found that commuting distance increases workers' absenteeism. Lindström (2008) and Frank et al. (2004) showed that a longer commuting time is related to a higher body mass index (BMI). The latter also showed that each additional hour spent in a car per day was associated with a $6 \%$ 
increase in the likelihood of obesity. Hansson et al. (2011) related commuting time to several health outcomes, such as mental health and self-rated health. Whereas they found that commuting time is negatively related to self-rated health and sleep quality, they do not find a significant relation between commuting time and mental health. One disadvantage of these studies is that they use cross-sectional data so that the findings could reflect spurious correlations due to unobserved characteristics of the individuals.

The literature dealing with the relation between commuting time and well-being does take these unobserved factors into account. Using the German Socio-Economic Panel in an FE model, Stutzer and Frey (2008) found that commuting time is negatively related to life satisfaction. Roberts et al. (2011) used the panel structure of the BHPS to analyze the relation between commuting time and well-being as measured by the

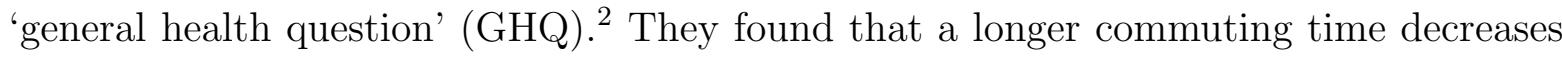
mental well-being only for women, not for men ${ }^{3}$ This finding is supported by Dickerson et al. (2014), who analyzed several FE models using the BHPS. However, they found no significant relation between commuting time and overall life satisfaction, in contrast to the findings of Stutzer and Frey (2008).

Based on the literature, I expect the following:

- Longer commuting time negatively affects subjective health;

- Longer commuting time negatively affects objective health;

- Longer commuting time negatively affects health behavior;

- Longer commuting time results in higher health care utilization through lower (subjective and/or objective) health.

The literature dealing with stress levels suggest that the health effects of commuting could be heterogeneous. Wener and Evans (2011) compared the stress effects of commuting for car drivers and those using public transportation. They found greater stress among car drivers than among bus commuters. Other studies relate commuting time to measures such as stress and blood pressure among car drivers and among

\footnotetext{
${ }^{2}$ The GHQ score is the sum of the responses to 12 questions related to mental health.

${ }^{3}$ This is in contrast to the cross-sectional study of Hansson et al. (2011), which reports no significant relation between commuting time and mental health.
} 
individuals using public transportation. Car driving in commuting has been found to elevate physiological markers of stress such as blood pressure and neuroendocrine hormone levels (e.g., Robinson 1991; Bellet et al. 1969; Simonson et al. 1968). Moreover, highway congestion increases blood pressure among car drivers (e.g., White and Rotton 1998; Evans and Carrère 1991; Schaeffer et al. 1988; Novaco et al. 1979; Stokols et al. 1978). Public transportation commuting in especially crowded trains has been found to increase physiological stress (e.g., Cox et al. 2006; Singer et al. 1974). Wener et al. (2003) found that shortened commuting times due to changed rail routes improved, for example, neuroendocrine hormones levels, indicating lower stress levels.

Novaco et al. (1991) found that stress perceived as due to commuting also differs across gender. Women report higher stress levels due to commuting than men. This, in turn, could result in stronger negative health effects of commuting for women than for men. Roberts et al. (2011) provided another possible mechanism for heterogeneous commuting effects across gender. They provided evidence that the negative relation between commuting time and well-being holds only for women and is not due a shorter work week or occupational segregation but, rather, due to greater responsibility for housework and childcare compared to men.

Based on the literature on the heterogeneous effects of commuting on stress, I expect the following:

- The relation between commuting time and health is more pronounced among car drivers than among those using public transportation;

- The relation between commuting time and health is more pronounced among women than among men.

\section{$3 \quad$ Data and descriptive statistics}

\subsection{Data}

In this paper, I use 18 waves of data from the BHPS. The BHPS is a representative sample of individuals living in the United Kingdom. This longitudinal sample includes over 5,000 households, containing over 10,000 individuals. 
Commuting The BHPS covers information on commuting time and mode from 1991 to 2008.4 Commuting time is defined as the total time in minutes individuals need to go from home to work (one way).$^{5}$ Figure 2 plots the average commuting time per year (over both active and passive commuters).$^{6}$ The figure shows a clear though small increase in the average commuting time, from 22.8 minutes in 1992 to 24.6 minutes in 2007 (one way).

Whereas the average commuting time does vary only slightly over the years, individuals change their commuting times quite often 7 Only $45 \%$ of commuters did not change their commuting time from one year to the next; $26 \%$ of individuals changed their commuting time by 10 minutes or more over any two consecutive years and $42 \%$ did so over any five consecutive years. The average standard deviation of commuting times at the individual level is 8.3 minutes. Only $12 \%$ of respondents did not change their commuting time during all available years of data 8

[Figure 2 around here]

In the analyses, I restrict the sample to full-time workers in employment aged between 18 and 65. As Roberts et al. (2011), I exclude the self-employed, since they are more likely to have a workplace at home and have different commuting patterns compared to employees. Part-time workers are excluded for similar reasons 9 Moreover, I

\footnotetext{
${ }^{4}$ Whereas the BHPS respondents are part of the second wave of the BHPS's successor, Understanding Society, several outcome variables are no longer part of Understanding Society from the second wave onward.

${ }^{5}$ Information on commuting distance is not available in the BHPS.

${ }^{6}$ This figure covers all individuals who report they commute to work, including those who walk all way or ride a bicycle. Those who report being homeworkers, thus working entirely from home (less than $1 \%$ of the sample) are excluded.

${ }^{7}$ This was also pointed out by Dargay and Hanly $(2003)$, who also used the BHPS.

${ }^{8}$ To analyze how sensitive the results are with respect to possible endogenous changes in commuting times and possible measurement errors in commuting times, I perform two robustness checks. First, I estimate the model for a sub-sample of commuters who did not change their job, home, or commuting mode and, thus, for whom changes in commuting time were exogenous. Second, I estimate a model that includes an ordinal measure of commuting time to reduce possible measurement error. Both robustness checks provide findings similar to those of the main model.

${ }^{9}$ Whereas $87 \%$ of full-time workers are passive commuters (with an average one-way commuting time of 23.8 minutes), only $73 \%$ of part-time workers are (with an average one-way commuting time of 16.9 minutes). The findings for subjective health and health care utilization do not change if part-time workers are included in the model. Whereas commuting is no longer related to health problems, regular exercise, and BMI when part-timers are included, the relation between commuting and sickness absence does become significant when part-time workers are included.
} 
exclude individuals who either walk all the way to work or use a bicycle, since correlations between commuting and health outcomes are shown to be different for passive versus active commuters (e.g., Hansson et al. 2011; Lindstrom 2008; Gatersleben and Uzzell 2007) 10 The (passive) commuting modes included are rail/train, underground/tube, bus or coach, motorcycle/moped, car or van, and car/van passenger. Individuals who report being homeworkers are not part of the sample either ${ }^{11}$ This leaves a sample of 73,965 person-year observations on the commuting times for 14,114 distinct individuals.

[Figure 3 around here]

Whereas in 1991, 85\% of the full-time working people in the United Kingdom reported going to work using a passive commuting mode, in 2008 this percentage increased to $89 \%$. Figure 3 plots the distribution of commuting times in the United Kingdom for passive commuters ${ }^{12}$ Most people in the United Kingdom commute at least 10 minutes and less than 20 minutes one way, with an average commuting time of just over 25 minutes. About $95 \%$ of the sample has a one-way commuting time of one hour at most.

Women who work full-time have, on average, a commuting time slightly below that of men. Whereas women commute, on average, 24 minutes, men commute, on average, 26 minutes. There is also a difference in transportation modes across genders. Whereas $71 \%$ of the women drive by car to work, $80 \%$ of men do. Both differences across genders are significant.

Health outcomes I focus on four different types of health outcomes, as follows.

1. Subjective health. With respect to subjective health, there is information on health satisfaction (on a seven-point Likert scale) and health status over the last year (on a five-point Likert scale). For these subjective health measures, a higher score means better health 13

\footnotetext{
${ }^{10}$ Including active commuting modes and simultaneously including dummy variables for each possible commuting mode do not change the relation between commuting time and health. The results are available upon request.

${ }^{11}$ In a robustness check, I report the findings of a model that includes these individuals.

${ }^{12}$ Commuting times, in minutes, are cleaned by year by dropping observations above the 99 th percentile, which includes one-way commuting times of more than 90 minutes to 600 minutes.

${ }^{13}$ These two subjective health measures could differ, for example, due to the adaptation effect of health conditions.
} 
2. Objective health. The first measure of objective health is whether someone has been diagnosed with health problems involving at least one of the following: (1) arms, legs, hands, feet, back or neck, (2) sight, (3) hearing, (4) skin conditions/ allergies, (5) chest/breathing problems, asthma, bronchitis, (6) stomach, liver, kidneys or digestive problems, (7) diabetes, (8) anxiety, depression, bad nerves or psychiatric problems (9) alcohol or drug related problems, (10) epilepsy, (11) migraine or frequent headaches, (12) cancer, (13) stroke, and (14) other. The cancer and stroke items have been part of the survey since 2001. The second objective health measure is whether someone called in sick during the last year.

3. Health behavior. The health behavior variables are regular exercise (playing sports, doing aerobics or doing some other keep fit activity about once a week or more versus less than once a week) and BMI. Even though the BMI is, strictly speaking, not a measure of health behavior, it does reflect the consumption of good health behavior (e.g., nutrition and exercise) and is commonly used as such (e.g., Reinhold and Jürges 2010.

4. Health care utilization. Information on health care utilization contains, first, the number of visits to a general practitioner in the last year, grouped as follows: none, one or two, three to five, six to 10 , and more than 10 . The second variable is whether any in-patient hospital visits were made in the last year.

Most of these health outcomes are available in every wave. Health satisfaction was asked from 1996 to 2000 and from 2002 to 2008. Information on regular exercise was asked after 1996 and gathered every other year. The BMI is available only for 2004, 2006, and 2008. For summary statistics on the health and control variables, see Table 1.

Control variables I control for the following individual characteristics: age, gender, number of children, marital status, relationship to household head, highest educational qualification, and job tenure. Moreover, region and year dummies are included. This set of control variables is common in the literature on health outcomes such as heath satisfaction, BMI, and sickness absence (e.g., Rietveld et al. 2014; Roberts et al. 2011; Hansson et al., 2011; Stutzer and Frey 2008). 
The literature dealing with the health consequences of commuting is inconsistent in terms of including potential compensating factors such as (household) income. Hansson et al. (2012) included proxies for job strain, financial stress, and variables related to income, overtime, and unemployment history. Roberts et al. (2011) included housing quality, job satisfaction, and net household income. By including these potential compensating factors, these two studies specifically analyzed whether the relation between commuting and well-being is (partly) driven by the compensating factors included. This (potential) compensating role was exactly the reason for Stutzer and Frey (2008) not including household income, labor income, or working hours in their analyses on the relation between commuting and life satisfaction. They argued that the role of commuting could only be accurately predicted if all channels for compensation remain uncontrolled. If, for example, income is controlled for, people who spend more time commuting are, ceteris paribus, worse off (Stutzer and Frey 2008).

In this paper, I do not aim to analyze the role of compensating factors such as job characteristics (e.g., job strain) or housing quality in the relation between commuting and health. Nevertheless, in a robustness check, I include net household income, overtime hours, and length of current employment spell (since people could get used to commuting and to work-related stress or other work-related factors) to see how sensitive the results are to including variables with potentially compensating power.

\section{Empirical strategy}

The longitudinal characteristic of the BHPS allows the estimation of FE models in which idiosyncratic effects that are time invariant can be controlled for ${ }^{14}$ The effect of commuting time on health measures is then identified by the variation in commuting time within observations for the same individual. Equation 1 summarizes the empirical model:

$$
H_{i t}=\alpha_{i}+\beta C T_{i t}+\gamma C T 2_{i t}+\lambda X_{i t}+\varepsilon_{i t}
$$

\footnotetext{
${ }^{14}$ Ordinary least squares (OLS) analyses, as well as errors-in-variables regressions, do not reveal any significant relation between commuting time and health. This is probably due to unobserved idiosyncratic effects opposing the effect of commuting on health.
} 
where $H_{i t}$ denotes the individual's health $\alpha_{i}$ denotes time-invariant idiosyncratic effects, $\beta$ is the coefficient of commuting time $(C T)$, and $\gamma$ is the coefficient of its squared term (CT2). To evaluate the effect of commuting time on health, one needs to perform a test for joint significance. The vector $X$ includes all the control variables.

I argue that the findings of Equation 1 can be interpreted as causal effects. First, the FE model eliminates time-invariant idiosyncratic effects. Second, endogenous selection, namely, that commuting time can only be observed for people who are healthy enough to work (full time), can only bias the relation between commuting time and health downward. This is confirmed by a probit analysis in which "quitting on the job due to health reasons" is estimated on lagged commuting time and a set of control variables. This analysis yields a weak significant and negative relation between commuting time in year $t-1$ and the probability of quitting one's job due to health reasons in year $t t^{16}$ Therefore, my estimates can be seen as a lower bound.

I perform several robustness checks to test the sensitivity of the main findings. They can be grouped into two categories. First, I alter the methodology. I estimate a model in which I attempt to deal with possible measurement errors in reported commuting times. In this model, I do not include commuting time as a continuous variable, but as an ordinal measure ${ }^{17}$ Moreover, I estimate FE (ordered) logit models for the appropriate dependent variables to take into account their nonlinearity. Following Baetschmann et al. (2014), I estimate the "blow-up and cluster" (BUC) estimator. This estimator is an application of composite likelihood estimation (Mukherjee et al. 2008). According to Baetschmann et al. (2015), the BUC estimator is a consistent (though not the most efficient) estimator, in contrast to the estimator proposed by Ferrer-i Carbonell and Frijters (2004). In the third robustness check, I estimate random effects (ordered) probit models with Mundlak effects (Mundlak 1978). In the last robustness check related to methodology issues, I include three additional control variables that are potentially compensating factors: net

\footnotetext{
${ }^{15}$ In the main analyses, I treat the dependent variables as continuous. Thereby the coefficients can be interpreted as marginal effects. In the robustness analyses I perform alternative specifications such as FE (ordered) logit and random effects (ordered) probit with Mundlak terms.

${ }^{16}$ The findings are available upon request.

${ }^{17}$ Roberts et al. (2011) included a similar robustness check. However, whereas they defined dummy variables for commuting more than 20 minutes, 30 minutes, 45 minutes, and 60 minutes for separate analyses, I include an ordinal measure of commuting time.
} 
household income, overtime hours, and length of current employment spell to see how sensitive the results are to including variables with potentially compensating power ${ }^{18}$

In a second set of robustness checks, I analyze the relation between commuting time and health measures for several sub-groups. The first sub-sample in this context consists of all commuters who did not change commuting mode during all the BHPS waves in which they participated, to see whether those changing commuting modes impact my results. With the second sub-sample, I follow Roberts, Hodgson, and Dolan (2011), who argued that analyses of a sub-sample of commuters who do not change job, home, or commuting mode (in the last year) reveal the effect of exogenous changes in commuting time on well-being 19 Third, since commuting times in Greater London are much longer than in other parts of Britain, I estimate a model that excludes Greater London 20 Fourth, I estimate a model that also includes a small fraction of workers (less than 1\%) who report working entirely at home and thus do not experience any commuting time.

To analyze whether commuting time has heterogeneous health effects, I also estimate Equation 1 separately for car drivers and those using public transportation to go to work ${ }^{21}$ I also analyze heterogeneous effects across gender, since Roberts et al. (2011) have shown that commuting time affects well-being for women, but not for men.

\section{Results}

\subsection{Commuting time and health outcomes}

Table 2 reports the FE estimates on subjective and objective health outcomes. In the analyses, I control for several worker and job characteristics 22 Since commuting time $(C T)$ and its square $(C T 2)$ are included, the table also reports the F-statistics and p-

\footnotetext{
${ }^{18}$ Including three digit occupational codes or gross hourly wages gives similar results as including net household income.

${ }^{19}$ Unfortunately, the BHPS does not include information on workplace relocation, so one cannot rule out that such relocations apply to this sub-sample. However, to the extent that relocations are imposed on employees, they also comprise an exogenous change in commuting.

${ }^{20}$ As mentioned by Benito and Oswald (2000), people living in London commute the longest.

${ }^{21}$ I include the information of everyone who drives to work by car (uses public transportation) in year $t$. Differences in commuting time within individuals driving a car (using public transportation) over at least two years enable this estimation. I do not consider those using a motorcycle/moped (1.25\% of the sample) or car/van passengers $(7.8 \%$ of the sample) separately, since these groups are relatively small.

${ }^{22}$ For a full list of control variables, see Section 3.1 .
} 
values of the joint significance. The joint significance tests indicate whether there is indeed a U-shaped relation between commuting time and health.23

Table 2 shows that people who spend more time commuting report lower health satisfaction and a lower current health status. Commuting time squared is positive in both models, suggesting that the negative relations flatten out. However, the turning point for health satisfaction is around 45 minutes of commuting time and around 50 minutes for health status. Since 85\% (90\%) of the people in the sample have a one-way commuting time of 45 minutes (50 minutes) at most, the negative linear relation between commuting time and health status and satisfaction holds for a substantial share of the sample. Whereas the effects are highly significant, their size is relatively small. An increase in commuting time of 20 minutes with an initial commuting time of 10 minutes is, on average, associated with a 0.05-point lower health satisfaction (on a seven-point scale) and a 0.02-point lower self-reported health status (one a five-point scale). ${ }^{24}$ This last result is in line with the finding of Hansson et al. (2011), that commuting time is related to lower self-rated health. However, whereas the latter study is based on crosssectional data, I show that the relation between commuting time and subjective health outcomes also holds when taking into account fixed unobserved effects.

Table 2 also reports the regression results on objective health outcomes. I find that commuting time and the probability of having at least one health problem involving, for example, heart/blood pressure, diabetes, or migraines, are borderline significantly related (at the 10\% level) in a U-shaped manner. The turning point is around 45 minutes. A significant relation between commuting time and sickness absence is not found. So, even though the findings show that those individuals commuting longer have lower subjective health, they do not call in sick more often than those with shorter commuting times. This finding is in contrast to studies that deal with the cross-sectional relation between commuting time and sickness absence (Hansson et al. 2011; Kluger 1998; Costal

\footnotetext{
${ }^{23}$ In the absence of a (inverse) U-shaped relation, models are estimated which only include $C T$. I report on these findings in footnotes.

${ }^{24}$ Although the effects are small $(3.6 \%$ and $2.8 \%$ of the standard deviation of health satisfaction and of self-rated health status, respectively), they are much larger than the effect of commuting time on the GHQ score (indicating mental health) as estimated by Roberts et al. (2011). They found a 0.11-point lower GHQ score (related to an identical increase in commuting time of 20 minutes) on a 36-point Likert scale.
} 
et al. 1988).

[Table 2 around here]

Table 3 shows the results of analyzing the measures for health behavior and health care utilization. In contrast to my expectations, I find no significant relation between commuting time and the probability of regular exercise ${ }^{25}$ The relation between commuting time and BMI is at the $10 \%$ level, significant in an inverse U-shaped manner. Those commuting longer have a higher BMI, but this positive relation decreases with longer commuting times.

Since I find that full-timers with longer commuting times have lower subjective health but do not seem to have lower objective health, it is a priori unclear what to expect from the relation between commuting time and health care utilization. Table 3 shows an inverse U-shaped relation between commuting time and the number of visits to a general practitioner. Additional analyses show that this significant relation between commuting time and the number of visits to the general practitioner disappears when the model includes either the respondent's health status or health satisfaction ${ }^{26}$ This indicates that commuting time affects the number of visits to the general practitioner only via lower subjective health. I find no significant relation between commuting time and the probability of an in-patient hospital stay, so the increase in health care utilization - via a lower subjective health - is restricted to basic health care ${ }^{27}$

\subsection{Robustness checks}

As described in Section 4, I perform several robustness checks to show the sensitivity of the main findings. Tables 4 and 5 report the results of models using different methodologies for subjective and objective health measures (Table 4) and health behavior and health care utilization (Table 5). Panel (a) of both tables includes an ordinal measure

\footnotetext{
${ }^{25} \mathrm{~A}$ linear relation between commuting time and the probability of regular exercise is absent as well.

${ }^{26}$ The results are available upon request.

${ }^{27} \mathrm{~A}$ linear relation between commuting time and the probability of an in-patient hospital stay is absent as well.
} 
of commuting time ${ }^{28}$ The reference group commutes less than five minutes. Column (1) shows that commuting more than 25 minutes results in significantly lower health satisfaction than commuting less than five minutes. Whereas the coefficients are already negative for commutes of more than 10 minutes, they do not turn out to be statistically significant. Nevertheless, all commuting time dummies are jointly significant. This also holds for health status. In line with the findings in Table 2, commuting time decreases self-perceived health status. Column (3) shows that all commuting time dummies together are not significantly related to the probability of having health problems at the $10 \%$ level, but are at the $15 \%$ level. Since this relation is only significant at the $10 \%$ in the main model, not much has changed here either. Nevertheless, the table shows that people commuting between 26 minutes and 30 minutes one way have a significantly larger probability of experiencing one or more health problems than those commuting less than five minutes one way. Column (4) shows a similar finding as in column (3): Whereas those commuting between 26 minutes and 30 minutes and those commuting between 16 minutes and 20 minutes have a larger probability of calling in sick than the reference group, overall, no significant relation between commuting time and calling in sick is observed. The findings reported in Table 5 with respect to health behavior and health care utilization are similar to the ones in Table 3. Including an ordinal measure of commuting time clearly shows a significant relation with the number of visits to the general practitioner as well. With respect to the other variables no or a weak significant relation with commuting time is found.

Panel (b) of Tables 4 and 5 estimates the FE (ordered) logit models. In line with Dickerson et al. (2014) and Ferrer-i Carbonell and Frijters (2004), the findings are robust to this type of methodology, in which the ordinal/dichotomous character of the dependent variables is taken into account as well. Whereas the sizes of the coefficients increase compared to the main models in which I estimate the FE OLS models, significance levels remain similar: A U-shaped relation with commuting time is found for both subjective health measures and no significant relation is found for sickness absence. The U-shaped relation between commuting time and the probability of health problems that was at the borderline of being weakly significant in the main model is significant only at the

\footnotetext{
${ }^{28}$ Since only $22 \%$ of the respondents never changed their ordinal categories during their participation in the BHPS, an FE method can be applied. An ordinal scale of 10-minute ranges per group provides similar findings.
} 
$13 \%$ level in panel (b) of Table 4. Estimation of the random effect models with Mundlak terms (panel c) also produces findings similar to those of the main model. This also holds for the variables with respect to health behavior and health care utilization (Table 2). In Panel (d), potentially compensating factors are included in the FE OLS models. As expected by Stutzer and Frey (2008), the relation between commuting time and all health measures (both Tables 4 and 5 ) is stronger than in the main model ${ }^{29}$

Tables 6 and 7 report the results for the models with different sub-samples. In panel (a), I restrict the sample to commuters who did not change commuting mode during the BHPS waves in which they participated. It turns out that there are no large differences between the main model and the sample that only includes workers who did not change commuting mode in all waves in which they participated. In panel (b), I restrict the sample to individuals who did not change house, job, or commuting mode compared to one year before. For this subsample, the U-shaped relation between commuting time and the probability of health problems is no longer (weakly) significant. For the other variables, similar results are found as in the main model. In panel (c), people who live in greater London are excluded. It turns out that the results are robust for this sub-sample as well. In panel (d), I extend the sample by also including workers who report working entirely at home and who thus have no commuting time at all.

Overall, the robustness checks confirm the general finding that whereas objective health and health behavior are barely affected by commuting time, subjective health measures are clearly lower for people who commute longer. Moreover, I again find that workers commuting longer visit the general practitioner more often.

\subsection{Mechanisms}

Even though the BHPS does not cover data on possible mechanisms that could drive the adverse effects of commuting time on subjective health, the 'innovation panel' of the UK household longitudinal study Understanding Society does. Understanding Society is a leading study of the socioeconomic circumstances and attitudes of 100,000 individuals in 40,000 British households and includes more information on nutrition and daily physical

\footnotetext{
${ }^{29}$ This has nothing to do with the smaller sample sizes due to the availability of the net household income, since the main model based on this restricted sample yields similar results to those reported in Table 2 .
} 
activities ${ }^{30}$ I perform descriptive and explorative OLS estimations that include commuting time and its square, as well as the control variables from the main analyses ${ }^{31}$ I find descriptive evidence for compensating health behavior among those with relatively long commuting times. First, I find they seem to eat healthier. Commuting time is positively related to both the number of days per week commuters eat fruits and vegetables and the number of usual portions of fruit and/or vegetables they eat on such days (see Table A1). Second, I find that those commuting longer participate in more physical activities: People who commute longer report more days in which they walked at least 10 minutes or 30 minutes (see Table A2).

The UK household longitudinal study includes next to the main panel the so-called 'innovation panel'. The innovation panel covers special topics that are not necessarily included in every wave. The fourth wave, for example, covers detailed information on commuting and sleep quality. I find that a longer commuting time is significantly related to lower overall sleep quality, which was also found by Hansson et al. (2011) for Sweden. Lower sleep quality could therefore explain part of the negative effect of commuting time on health.

The additional data from the UK household longitudinal study show that there is little evidence of nutrition and daily physical activity being the mechanism through which commuting time negatively affects health. Instead, those with a longer commuting time seem to compensate for it by better nutrition and more physical activity. This could explain why no significant relation is found between commuting time and objective health outcomes. Lower sleep quality among those commuting longer could explain their lower perceived health.

\subsection{Heterogeneous effects}

In this section, I analyze the heterogeneous effects of commuting time on health with respect to transportation mode and gender.

\footnotetext{
${ }^{30}$ It is important to distinguish between regular exercise and physical activities as the latter can be a byproduct of other activities such as taking up children from school, doing the groceries, or even commuting.

${ }^{31}$ The findings of the additional analyses and their explanations can be found in the Web Appendix, Tables A1 to A3. See https://sites.google.com/site/annemariekuennnelen/web-appendix-he.
} 
Commuting mode. Table 8 summarizes the heterogeneous health effects across commuting modes. It compares the findings for car drivers and those commuting by public transportation. For car drivers, a longer commuting time is related to lower health satisfaction, lower health status, and a higher BMI. Moreover and maybe due to these findings, car drivers with longer commuting times visit the general practitioner more often. For commuters using public transportation, I find no significant relation between commuting time and any of these health measures. Shown by the F-statistics for joint significance, which are significant only at the $10 \%$ level, commuting time is only weakly related to lower health satisfaction and health problems for the group of commuters using public transportation ${ }^{32}$ Overall, one can conclude from these findings that commuting time is, as expected, more negative for (perceived) health among car drivers than among commuters using public transportation 33 This is in line with the finding of Wener and Evans (2011), that the stress levels of car drivers are higher than those of workers using public transportation.

Again, the UK household longitudinal study provides the possibility of analyzing whether there are more mechanisms playing a role in the heterogeneous health effects of commuting across commuting modes (See Tables A1 to A3 in the Web Appendix). In addition to the question whether the respondents perform regularly exercise (that is available in the BHPS), there are two questions regarding physical activities: the number of days they walk 10 minutes and 30 minutes. For those using public transportation, I find that a longer commuting time is positively related to the number of days involving walking at least 10 minutes or 30 minutes. For car drivers, on the other hand, I find a negative relation between commuting time and these measures of daily physical activity. This difference turns out to be significant across transportation modes. Since more physical activity is likely to positively affect health, these findings could explain why workers using public transportation to go to work do not experience adverse health effects for longer commuting times. Since I find a negative relation between commuting time and sleep quality for car drivers only, this could also explain part of the differentiated health effects of commuting across modes of transportation 34

\footnotetext{
${ }^{32}$ There is no significant linear relation at the $5 \%$-level either.

${ }^{33}$ In case of an absent (inverse) U-shaped relation, linear relations have been tested, but these turn out to be absent as well.

${ }^{34}$ The finding that commuting time is negatively related to the sleep quality of only car drivers could, in turn, be explained by their greater stress perception compared to that of commuters using
} 
Gender. Table 9 shows differentiated effects across gender for several health measures. Among women, I find that a longer commuting time is significantly related to lower health satisfaction and a lower probability of regular exercise. Moreover, I find that women who commute longer have a larger probability of sickness absence and visit the general practitioner more often. Among men, commuting time is related to lower health status and, as among women, a higher number of visits to the general practitioner. The finding that only women exhibit a negative relation between commuting time and objective health as well as health behavior is interesting and could be explained by the results of Roberts et al. (2011), who found that the negative relation between commuting time and well-being for only women could be explained by their greater responsibility for housework and child care compared to men 35

Moreover, this idea that women have greater responsibility for housework and child care could explain the finding that women who commute longer have a lower probability of regular exercise, an effect that is not found for men. This lower physical activity can, in turn, explain the more pronounced adverse health effects of a longer commuting time for women compared to men ${ }^{36}$ Another explanation could be sleep quality, since I find that commuting time is more strongly related to lower sleep quality for women than for men (See Table A3 in the Web Appendix). Novaco et al. (1991) show that commuting time results in more stress for women than for men and thus provide another explanation why adverse health effects are more pronounced among women than among men.

\section{Conclusion}

In this paper, I analyze the relation between commuting time and health for full-time employed workers in the United Kingdom. I concentrate on the daily commute of those who use a car or public transportation. In contrast to most of the earlier research, my analyses focus on four types of health outcomes: subjective health, objective health,

public transportation (e.g., Wener and Evans 2011). However, the F-test for joint significance shows no significant difference between car drivers and those commuting by public transportation. I find no heterogeneous relation between commuting time and nutrition across modes of transportation.

${ }^{35}$ In case of an absent (inverse) U-shaped relation, linear relations have been tested, but these turn out to be absent as well.

${ }^{36}$ The relation between commuting time and measures of daily physical activity from the UK longitudinal study do not show differentiated effects across gender and neither do the nutrition variables. 
health behavior, and health care utilization. Moreover, in contrast to other studies relating commuting to health (e.g., Hansson et al. 2011; Lindström (2008)), I use FE analyses to control for unobserved time-invariant characteristics of individuals.

I find that whereas objective health and health behavior measures are barely affected by commuting time, subjective health is clearly lower for people who commute longer. I find that longer commuting times are related to lower health satisfaction and lower health status. Moreover, I find that whereas a longer commuting time is not related to a higher probability of an inpatient hospital stay, commuting time has an inverted U-shaped relation with the number of visits to the general practitioner. Altogether, my findings suggest that commuting time is (in the short run) related to minor health conditions, reflecting lower subjective health and consequently more visits to the general practitioner, but not to serious health conditions (leading to an inpatient hospital stay). Additional research focusing on the relation between commuting time and objective minor health problems such as a cold or the flu could further increase understanding of the relation between commuting time and health.

The health effects of commuting turn out to be heterogeneous across transportation modes and genders. Commuting time has a more negative effect on health (and is perceived as such) among car drivers than among commuters using public transportation. For car drivers, I find that a longer commuting time is related to lower health satisfaction, lower health status, and a higher BMI. Moreover, they visit the general practitioner more often. For commuters using public transportation, I find no significant relation between commuting time and any of these health measures. Heterogeneous effects are also found across gender. Women face more and stronger negative effects of longer commuting times. Whereas men who commute longer have a lower self-perceived health status, women report lower health satisfaction, a lower probability of regular exercise, and a higher BMI; call in sick more often; and visit the general practitioner more often than men.

I performed several explorative analyses on possible mechanisms. Using crosssectional data, I find significant conditional correlations between commuting time, on the one hand, and better nutrition and more physical activity, on the other hand. This could explain why I do not find any effects of commuting time on objective health measures. Distinguishing across commuting modes, I find a positive relation between commuting 
time and daily physical activity for those using public transportation. This could explain why the relation between commuting time and health is not significant for this group. Moreover, the significant relation between commuting time and lower sleep quality could explain why those with longer commuting times have lower self-perceived health. However, more research is needed on the causal mechanisms that drive the relation between commuting time and health.

Since commuting plays a big role in the everyday life of the European working population, the health effects of commuting should receive more attention. Almost 80\% of commuters use public transportation or a car to go to work. These two commuting modes are especially strongly related to several negative health outcomes. Long commuting times not only negatively affect different types of health outcomes but also have negative consequences on life satisfaction, stress, and family life as well (e.g., Stutzer and Frey 2008; Koslowsky et al. 1995). It is therefore important to find how to decrease people's daily commuting time. Wener et al. (2003) showed, for example, that the introduction of a direct train connection between New Jersey and New York City significantly reduced commuting times and thereby reduced perceived stress levels. The introduction of a direct connection is one way of decreasing commuting times and thereby reducing the negative health effects of commuting. It is important to investigate other ways to reduce commuting time, such as commuting outside of rush hours and even working from home, to hamper the negative health effects of commuting. 


\section{References}

Baetschmann, G., K. E. Staub, and R. Winkelmann (2014): "Consistent estimation of the fixed effects ordered logit model," Journal of the Royal Statistical Society: Series A (Statistics in Society), pp. n/a-n/a.

Bellet, S., L. Roman, And J. Kostis (1969): "The effect of automobile driving on catecholamine and adrenocortical excretion," The American Journal of Cardiology, $24(3), 365-368$.

Benito, A., And A. Oswald (2000): "Commuting in Great Britain in the 1990s," Discussion Paper 560, University of Warwick, Department of Economics.

Costal, G., L. Pickup, and V. Martino (1988): "Commuting: a further stress factor for working people: evidence from the European Community," International archives of occupational and environmental health, 60(5), 377-385.

Cox, T., J. Houdmont, And A. GRIffiths (2006): "Rail passenger crowding, stress, health and safety in Britain," Transportation Research Part A: Policy and Practice, $40(3), 244-258$.

Dargay, J., And M. Hanly (2003): "Travel to Work: an investigation based on the British Household Panel Survey," Mimeo.

Dickerson, A., A. R. Hole, And L. A. Munford (2014): "The relationship between well-being and commuting revisited: Does the choice of methodology matter?," Regional Science and Urban Economics, 49(0), 321 - 329.

Evans, G., And S. CARRÈre (1991): "Traffic congestion, perceived control, and psychophysiological stress among urban bus drivers.," Journal of Applied Psychology, $76(5), 658$.

Ferrer-i Carbonell, A., And P. Frijters (2004): "How Important is Methodology for the estimates of the determinants of Happiness?*," The Economic Journal, 114(497), 641-659.

Frank, L. D., M. A. Andresen, And T. L. Schmid (2004): "Obesity relationships with community design, physical activity, and time spent in cars," American journal of preventive medicine, 27(2), 87-96.

Gatersleben, B., And D. Uzzell (2007): "Affective appraisals of the daily commute," Environment and Behavior, 39(3), 416-431.

Gottholmseder, G., K. Nowotny, G. Pruckner, and E. Theurl (2009): "Stress perception and commuting," Health Economics, 18(5), 559-576.

Hansson, E., K. Mattisson, J. Bjork, P. Ostergren, and K. Jakobsson (2011): "Relationship between commuting and health outcomes in a cross-sectional population survey in southern Sweden," BMC Public Health, 11(1), 834.

Hennessy, D., and D. Wiesenthal (1999): "Traffic congestion, driver stress, and driver aggression," Aggressive Behavior, 25(6), 409-423. 
Kageyama, T., N. Nishikido, T. Kobayashi, Y. Kurokawa, T. Kaneko, and M. KabUto (1998): "Long commuting time, extensive overtime, and sympathodominant state assessed in terms of short-term heart rate variability among male whitecollar workers in the Tokyo megalopolis.," Industrial health, 36(3), 209-217.

Kluger, A. (1998): "Commute variability and strain," Journal of Organizational Behavior, 19(2), 147-165.

Koslowsky, M., A. Kluger, and M. Reich (1995): Commuting stress: causes, effects, and methods of coping. Springer US.

LindstRöM, M. (2008): "Means of transportation to work and overweight and obesity: a population-based study in southern Sweden," Preventive Medicine, 46(1), 22-28.

Lyons, G., and K. Chatterjee (2008): "A Human Perspective on the Daily Commute: Costs, Benefits and Trade-offs," Transport Reviews, 28(2), 181-198.

Mukherjee, B., J. Ahn, I. Liu, P. J. Rathouz, and B. N. SÁnchez (2008): "Fitting stratified proportional odds models by amalgamating conditional likelihoods," Statistics in medicine, 27(24), 4950-4971.

Mundlak, Y. (1978): "On the Pooling of Time Series and Cross Section Data," Econometrica, 46(1), pp. 69-85.

Novaco, R., W. Kliewer, and A. Broquet (1991): "Home environmental consequences of commute travel impedance," American Journal of Community Psychology, 19(6), 881-909.

Novaco, R., D. Stokols, J. Campbell, and J. Stokols (1979): "Transportation, stress, and community psychology," American Journal of Community Psychology, $7(4), 361-380$.

Reinhold, S., And H. Jürges (2010): "Secondary school fees and the causal effect of schooling on health behavior," Health Economics, 19(8), 994-1001.

Rietveld, C. A., H. van Kippersluis, and A. R. ThuriK (2014): "Selfemployment and health: barriers or benefits?," Health Economics, pp. n/a-n/a.

Roberts, J., R. Hodgson, and P. Dolan (2011): "It's driving her mad": Gender differences in the effects of commuting on psychological health," Journal of health economics, 30(5), 1064-1076.

Robinson, A. (1991): "Cancer deaths due to all causes, its relationship with vehicle travel in Australia, Japan and European countries," Medical hypotheses, 36(2), 166171.

Schaeffer, M., S. Street, J. Singer, and A. Baum (1988): "Effects of Control on the Stress Reactions of Commuters," Journal of Applied Social Psychology, 18(11), 944-957.

Simonson, E., C. Baker, N. Burns, C. Keiper, O. Schmitt, and S. StackHOUSE (1968): "Cardiovascular stress (electrocardiographic changes) produced by driving an automobile," American Heart Journal, 75(1), 125-135. 
Singer, J., U. Lundberg, and M. Frankenhaeuser (1974): "Stress on the train: A study of urban commuting," in Advances in environmental psyhology. The urban environment., ed. by A. Baum, J. Singer, and S. Valins, vol. 1. Lawrence Elrbaum Associates, Hillsdale, NJ.

Stokols, D., R. Novaco, J. Stokols, and J. Campbell (1978): "Traffic congestion, Type A behavior, and stress," Journal of Applied Psychology, 63(4), 467-480.

Stutzer, A., And B. Frey (2008): "Stress that Doesn't Pay: The Commuting Paradox," The Scandinavian Journal of Economics, 110(2), 339-366.

van Ommeren, J. N., and E. GutiérRez-i Puigarnau (2011): "Are workers with a long commute less productive? An empirical analysis of absenteeism," Regional Science and Urban Economics, 41(1), 1-8.

Walsleben, J. A., R. G. Norman, R. D. Novak, E. B. O’Malley, D. M. Rapoport, and K. Strohl (1999): "Sleep habits of Long Island Rail Road commuters.," Sleep, 22(6), 728-734.

Wener, R., And G. Evans (2011): "Comparing stress of car and train commuters," Transportation Research Part F: Traffic Psychology and Behaviour, 14(2), 111-116.

Wener, R., G. Evans, D. Phillips, and N. Nadler (2003): "Running for the 7: 45: The effects of public transit improvements on commuter stress," Transportation, $30(2), 203-220$.

White, S., And J. Rotton (1998): "Type of Commute, Behavioral Aftereffects, and Cardiovascular Activity A Field Experiment," Environment and Behavior, 30(6), 763780 . 


\section{A Tables and figures}

Figure 1: Commuting time in Europe

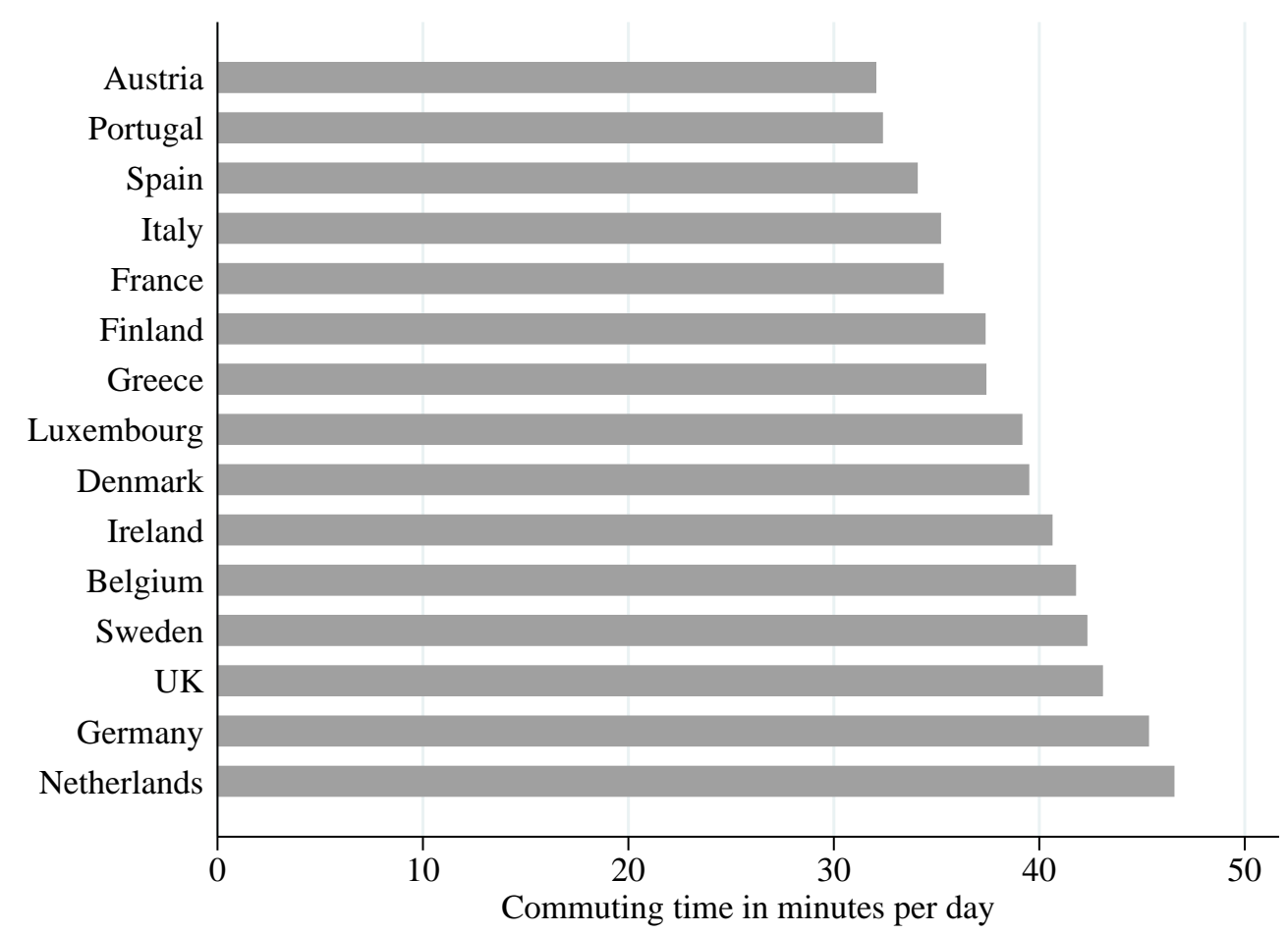

Source: European Working Conditions Survey (2005).

Note: The figure denotes commuting minutes per day, thereby referring to two-way times. 
Figure 2: Commuting time over the years in the United Kingdom

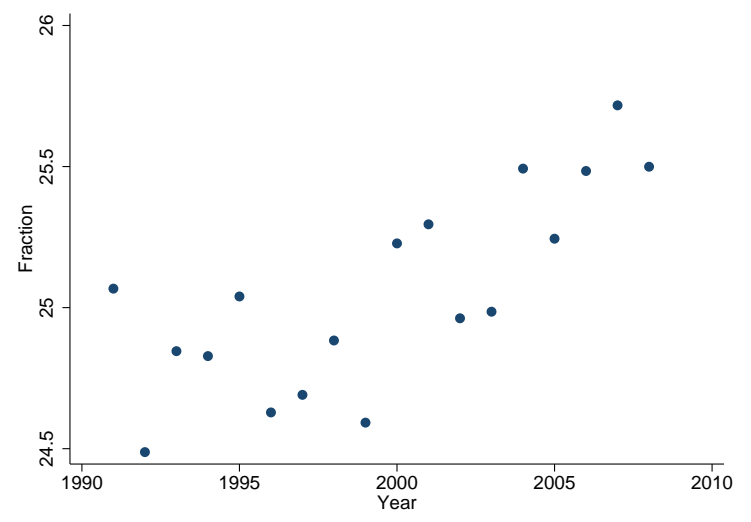

Source: BHPS (1991-2008) 
Figure 3: Distribution of commuting time in the U.K.

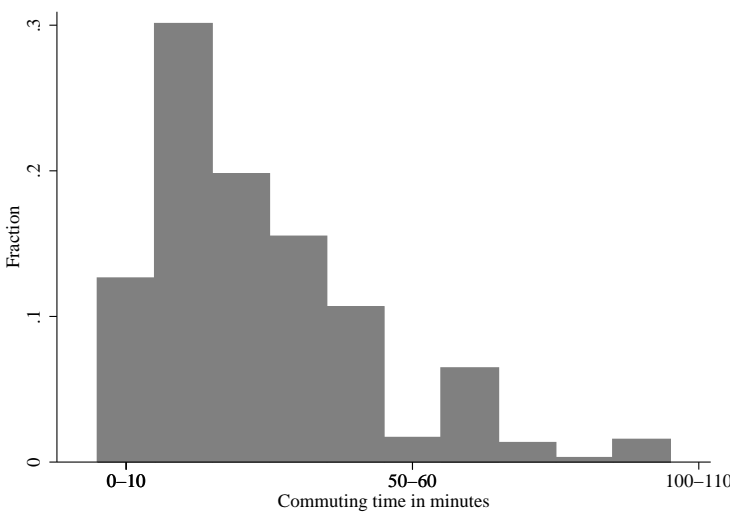

Source: BHPS (1991-2008)

Note: Observations are grouped in 10 minutes-intervals. 
Table 1: Summary statistics

\begin{tabular}{lrrrr}
\hline \hline & Mean & Std. Dev. & Min & Max \\
Health satisfaction & 5.19 & 1.37 & 1 & 7 \\
Health status & 4.04 & 0.82 & 1 & 5 \\
Health problems & 0.48 & 0.50 & 0 & 1 \\
Sickness absence & 0.02 & 0.13 & 0 & 1 \\
Regular exercise & 0.48 & 0.50 & 0 & 1 \\
BMI & 26.43 & 4.28 & 5 & 41.52 \\
Nr. visits to general practitioner & 1.14 & 1.05 & 0 & 4 \\
In-patient hospital stay & 0.07 & 0.25 & 0 & 1 \\
\hline Commuting time & 25.10 & 18.24 & 0 & 90 \\
\hline Age & 38.18 & 11.51 & 18 & 65 \\
Female & 0.42 & 0.49 & 0 & 1 \\
Number of children & 0.56 & 0.91 & 0 & 7 \\
Highest qualification level* & 5.50 & 2.97 & 1 & 12 \\
Relation to household head* & 2.27 & 3.15 & 1 & 30 \\
Marital status* & 2.45 & 2.02 & 0 & 10 \\
\hline Length (days) of current labour market spell & 1828.34 & 2240.06 & 0 & 29986 \\
Overtime hours & 4.24 & 5.77 & 0 & 30 \\
Gross hourly wage & 9.64 & 4.95 & 0.005 & 31.09 \\
\hline \hline
\end{tabular}

Note: Region and year dummies are included in the analyses as well. ${ }^{*}$ For each possible value, a dummy variable is included in the analyses. 
Table 2: Estimation results on subjective and objective health outcomes

\begin{tabular}{lllll}
\hline \hline & $(1)$ & $(2)$ & $(3)$ & $(4)$ \\
& Health satisfaction & Health status & Health problems & Sickness absence \\
Commuting time & $-0.0043^{* * *}$ & $-0.0019^{* * *}$ & $0.0008^{* *}$ & 0.0002 \\
& $(0.0013)$ & $(0.0007)$ & $(0.0004)$ & $(0.0001)$ \\
Commuting time squared & $4.49 \mathrm{e}-05^{* * *}$ & $1.90 \mathrm{e}-05^{* *}$ & $-9.01 \mathrm{e}-06^{* *}$ & $-1.83 \mathrm{e}-06$ \\
& $(1.53 \mathrm{e}-05)$ & $(8.05 \mathrm{e}-06)$ & $(4.37 \mathrm{e}-06)$ & $(1.60 \mathrm{e}-06)$ \\
\hline Individuals & 11693 & 13702 & 14065 & 14067 \\
Observations & 50503 & 66857 & 71559 & 71609 \\
\hline F-statistic for joint significance & 4.74 & 3.41 & 1.87 & 1.46 \\
(p-value) & 0.0087 & 0.0329 & 0.1538 & 0.2323 \\
\hline \hline
\end{tabular}

Model: FE OLS

Note: Only the coefficients for the commuting variables are reported. The following control variables are included: age, age squared, number of children, relation to household head, marital status, highest education level, region and year dummies. * $\mathrm{p}<0.1 ; * * \mathrm{p}<0.05 ; * * *<0.01$. 
Table 3: Estimation results on health behavior and health care utilization outcomes

\begin{tabular}{lllll}
\hline \hline & $(1)$ & $(2)$ & $(3)$ & $(4)$ \\
& Regular & BMI & Nr. visits & $\begin{array}{l}\text { In-patient } \\
\text { hospital stay }\end{array}$ \\
& exercise & & general practitioner & ho005* \\
Commuting time & $-0.0012^{*}$ & $0.0156^{*}$ & $0.0029^{* * *}$ & $(0.0002)$ \\
& $(0.0007)$ & $(0.0090)$ & $(0.0008)$ & $-5.19 \mathrm{e}-06^{*}$ \\
Commuting time squared & $1.61 \mathrm{e}-05^{*}$ & -0.0001 & $-3.99 \mathrm{e}-05^{* * *}$ & $(2.99 \mathrm{e}-06)$ \\
& $(8.50 \mathrm{e}-06)$ & $(0.0001)$ & $(1.02 \mathrm{e}-05)$ & 14066 \\
\hline Individuals & 10599 & 5240 & 14059 & 71589 \\
Observations & 29387 & 7228 & 71563 & 1.75 \\
\hline F-statistic for joint significance & 1.76 & 2.86 & 6.75 & 0.1742 \\
(p-value) & 0.1723 & 0.0572 & 0.0012 & \\
\hline \hline
\end{tabular}

Model: FE OLS

Note: Only the coefficients for the commuting variables are reported. The following control variables are included: age, age squared, number of children, relation to household head, marital status, highest education level, region and year dummies. ${ }^{*} \mathrm{p}<0.1 ; * * \mathrm{p}<0.05 ; * * *<0.01$. 
Table 4: Robustness checks for subjective and objective health measures - methodology

\begin{tabular}{|c|c|c|c|c|}
\hline \multirow[b]{4}{*}{ Commuting time $<=5$ minutes } & \multicolumn{4}{|c|}{ Panel a: Ordinal commuting time } \\
\hline & (1a) & $(2 \mathrm{a})$ & (3a) & $(4 a)$ \\
\hline & Health satisfaction & Health status & Health problems & Sickness absence \\
\hline & & & ref & ref \\
\hline Commuting time 6-10 minutes & 0.011 & $-0.023^{*}$ & 0.000 & 0.003 \\
\hline Commuting time $11-15$ minutes & -0.028 & $-0.027^{*}$ & 0.010 & 0.004 \\
\hline Commuting time $16-20$ minutes & -0.027 & $-0.045^{* * *}$ & 0.003 & $0.006^{* *}$ \\
\hline Commuting time 21-25 minutes & -0.012 & -0.017 & 0.007 & 0.003 \\
\hline Commuting time $26-30$ minutes & $-0.078^{* * *}$ & $-0.054^{* * *}$ & $0.018^{* *}$ & $0.008^{* * *}$ \\
\hline Commuting time $31+$ minutes & $-0.056^{* *}$ & $-0.043^{* * *}$ & 0.010 & 0.004 \\
\hline F-statistic for joint significance & 2.72 & 3.08 & 1.58 & 1.52 \\
\hline (p-value) & 0.0123 & 0.0051 & 0.1476 & 0.1676 \\
\hline Individuals & 11693 & 13702 & 14065 & 14067 \\
\hline \multirow[t]{3}{*}{ Observations } & 50503 & 66857 & 71559 & 71609 \\
\hline & & Panel b: FE & (ordered) logit & \\
\hline & $\begin{array}{l}\text { (ID) } \\
\text { Health satisfaction }\end{array}$ & $\begin{array}{l}\text { (2b) } \\
\text { Health status }\end{array}$ & $\begin{array}{l}\text { (3b) } \\
\text { Health problems }\end{array}$ & $\begin{array}{l}(4 \mathrm{~b}) \\
\text { Sickness absence }\end{array}$ \\
\hline Commuting time $(\mathrm{CT})$ & $-0.0089^{* * *}$ & $-0.0070^{* *}$ & $0.0061^{* *}$ & 0.0140 \\
\hline Commuting time squared (CT2) & $1.12 \mathrm{e}-04^{* * *}$ & $5.77 \mathrm{e}-05$ & $-0.0001^{*}$ & -0.0001 \\
\hline F-statistic for joint significance & 8.74 & 8.37 & 4.11 & 3.27 \\
\hline (p-value) & 0.0126 & 0.0153 & 0.1280 & 0.1947 \\
\hline Individuals & 3974 & 4241 & 5021 & 978 \\
\hline \multirow[t]{4}{*}{ Observations } & 116230 & 69505 & 39387 & 8178 \\
\hline & Panel c & RE (ordered & probit with $\mathrm{M}$ & ndluk \\
\hline & (1c) & $(2 \mathrm{c})$ & $(3 \mathrm{c})$ & $(4 c)$ \\
\hline & Health satisfaction & Health status & Health problems & Sickness absence \\
\hline Commuting time $(\mathrm{CT})$ & $-0.0048^{* * *}$ & $-0.0028^{* *}$ & $0.0029^{*}$ & 0.0021 \\
\hline Commuting time squared (CT2) & $4.91 \mathrm{e}-05^{* * *}$ & $3.02 \mathrm{e}-05^{* *}$ & $-3.44 \mathrm{e}-05^{*}$ & $-2.89 \mathrm{E}-05$ \\
\hline F-statistic for joint significance & 17.11 & 6.81 & 3.51 & 0.75 \\
\hline (p-value) & 0.0002 & 0.0332 & 0.1726 & 0.6863 \\
\hline Individuals & 11693 & 13702 & 14063 & 14021 \\
\hline \multirow{4}{*}{ Observations } & 50503 & 66857 & 71549 & 71442 \\
\hline & \multicolumn{4}{|c|}{ Panel d: Including compensating factors } \\
\hline & $(1 \mathrm{~d})$ & $(2 \mathrm{~d})$ & $(3 \mathrm{~d})$ & $(4 \mathrm{~d})$ \\
\hline & Health satisfaction & Health status & Health problems & Sickness absence \\
\hline Commuting time (CT) & $-0.0073^{* * *}$ & $-0.0032^{* * *}$ & $0.0013^{* * *}$ & $0.0004^{* *}$ \\
\hline Commuting time squared (CT2) & $0.0001 * * *$ & $2.92 \mathrm{e}-05^{* *}$ & $-1.38 \mathrm{e}-05^{* *}$ & $-4.84 \mathrm{e}-06 * *$ \\
\hline F-statistic for joint significance & 6.61 & 6.95 & 3.59 & 2.29 \\
\hline (p-value) & 0.0013 & 0.001 & 0.0275 & 0.1009 \\
\hline Individuals & 8644 & 10558 & 10934 & 10936 \\
\hline Observations & 25170 & 38923 & 43023 & 43071 \\
\hline
\end{tabular}

Note: Only the coefficients for the commuting variables are reported. Like in the main tables, the following control variables are included: age, age squared, number of children, relation to household head, marital status, highest education level, region and year dummies. Due to the iteration process, panel (b) does not include the variables relation to household head, marital status and year dummies. Panel (d) includes the following compensating factors in addition to the normal control variables: net household income (constructed by researchers at the Institute of Social and Economic Research, see Data Archive SN 3909-BHPS Derived Current and Annual Net Household Income Variables, Waves 1-14, 1991-2005), overtime hours and the length of the current employment spell. ${ }^{*} \mathrm{p}<0.1 ; * * \mathrm{p}<0.05 ; * * *<0.01$. 
Table 5: Robustness checks for health behavior and health care utilization - methodology

\begin{tabular}{|c|c|c|c|c|}
\hline & \multicolumn{4}{|c|}{ Panel a: Ordinal commuting time } \\
\hline & $(1 \mathrm{a})$ & $(2 \mathrm{a})$ & $(3 \mathrm{a})$ & $(4 a)$ \\
\hline & Regularly sports & BMI & Nr. visits & In-patient \\
\hline & & & general practitioner & hospital stay \\
\hline Commuting time $<=5$ minutes & ref & ref & ref & ref \\
\hline Commuting time $6-10$ minutes & -0.002 & -0.019 & $0.035^{* *}$ & -0.005 \\
\hline Commuting time $11-15$ minutes & -0.011 & -0.073 & $0.047^{* * *}$ & 0.007 \\
\hline Commuting time 16 -20 minutes & $-0.028^{*}$ & -0.031 & $0.045^{* *}$ & 0.003 \\
\hline Commuting time $21-25$ minutes & -0.014 & 0.272 & $0.057^{* *}$ & -0.001 \\
\hline Commuting time $26-30$ minutes & -0.014 & 0.270 & $0.066^{* * *}$ & 0.007 \\
\hline Commuting time $31+$ minutes & -0.016 & 0.311 & $0.035^{*}$ & 0.005 \\
\hline F-statistic for joint significance & 0.84 & 1.45 & 2.39 & 1.92 \\
\hline (p-value) & 0.5398 & 0.1913 & 0.0262 & 0.0734 \\
\hline Individuals & 10599 & 5240 & 14059 & 14066 \\
\hline \multirow[t]{5}{*}{ Observations } & 29387 & 7228 & 71563 & 71589 \\
\hline & \multicolumn{4}{|c|}{ Panel b: FE (ordered) logit } \\
\hline & $(1 b)$ & $(2 b)$ & $(3 \mathrm{~b})$ & $(4 b)$ \\
\hline & Regularly sports & BMI & Nr. visits & In-patient \\
\hline & & & general practitioner & hospital stay \\
\hline Commuting time (CT) & -0.0070 & $\mathrm{x}$ & $0.0120 * * *$ & $0.0100 * *$ \\
\hline Commuting time squared (CT2) & $0.0001^{* *}$ & $\mathrm{x}$ & $-1.57 \mathrm{e}-04^{* * *}$ & $-0.0001^{*}$ \\
\hline F-statistic for joint significance & 4.33 & $\mathrm{x}$ & 12.24 & 5.25 \\
\hline (p-value) & 0.1148 & $\mathrm{x}$ & 0.0022 & 0.0726 \\
\hline Individuals & 4206 & $\mathrm{x}$ & 3386 & 2942 \\
\hline \multirow[t]{5}{*}{ Observations } & 17397 & $\mathrm{x}$ & 55397 & 23937 \\
\hline & \multicolumn{4}{|c|}{ Panel c: RE (ordered) probit with Mundluk } \\
\hline & $(1 \mathrm{c})$ & $(2 \mathrm{c})$ & $(3 \mathrm{c})$ & $(4 \mathrm{c})$ \\
\hline & Regularly sports & $\mathrm{BMI}$ & Nr. visits & In-patient \\
\hline & & & general practitioner & hospital stay \\
\hline Commuting time $(\mathrm{CT})$ & -0.0025 & $\mathrm{x}$ & $0.0034^{* * *}$ & 0.0021 \\
\hline Commuting time squared (CT2) & $3.36 \mathrm{E}-05$ & $\mathrm{x}$ & $-4.25 \mathrm{e}-05^{* * *}$ & $-2.11 \mathrm{E}-05$ \\
\hline F-statistic for joint significance & 1.74 & $\mathrm{x}$ & 12.40 & 2.13 \\
\hline (p-value) & 0.4193 & $\mathrm{x}$ & 0.0020 & 0.3449 \\
\hline Individuals & 10597 & $\mathrm{x}$ & 14059 & 14056 \\
\hline \multirow[t]{5}{*}{ Observations } & 29379 & $\mathrm{x}$ & 71563 & 71561 \\
\hline & \multicolumn{4}{|c|}{ Panel d: Including compensating factors } \\
\hline & $(1 d)$ & $(2 \mathrm{~d})$ & $(3 \mathrm{~d})$ & $(4 \mathrm{~d})$ \\
\hline & Regularly sports & BMI & Nr. visits & In-patient \\
\hline & & & general practitioner & hospital stay \\
\hline Commuting time $(\mathrm{CT})$ & -0.0021 & $\mathrm{x}$ & $0.0029^{* *}$ & $0.0006^{*}$ \\
\hline Commuting time squared (CT2) & $2.60 \mathrm{e}-05^{*}$ & $\mathrm{x}$ & $-3.86 \mathrm{e}-05^{* * *}$ & $-5.35 \mathrm{e}-06$ \\
\hline F-statistic for joint significance & 1.46 & $\mathrm{x}$ & 3.82 & 1.72 \\
\hline (p-value) & 0.2323 & $\mathrm{x}$ & 0.022 & 0.1793 \\
\hline Individuals & 7362 & $\mathrm{x}$ & 10931 & 10934 \\
\hline Observations & 14068 & $\mathrm{x}$ & 43042 & 43052 \\
\hline
\end{tabular}

Note: Only the coefficients for the commuting variables are reported. Like in the main tables, the following control variables are included: age, age squared, number of children, relation to household head, marital status, highest education level, region and year dummies. Due to the iteration process, panel (b) does not include the variables relation to household head, marital status and year dummies. Panel (d) includes the following compensating factors in addition to the normal control variables: net household income (constructed by researchers at the Institute of Social and Economic Research, see Data Archive SN 3909-BHPS Derived Current and Annual Net Household Income Variables, Waves 1-14, 1991-2005), overtime hours and the length of the current employment spell. Panel (d) is not available for BMI as the net household income variable is not available for the years 2004 and 2006 in which BMI is included in the BHPS.* $\mathrm{p}<0.1{ }^{* *} \mathrm{p}<0.05 ; * * *<0.01$. 
Table 6: Robustness checks for subjective and objective health measures - sub samples

\begin{tabular}{|c|c|c|c|c|}
\hline & \multicolumn{4}{|c|}{ Panel a: No change in commuting mode } \\
\hline & $(1 \mathrm{a})$ & $(2 \mathrm{a})$ & $(3 \mathrm{a})$ & $(4 a)$ \\
\hline & Health satisfaction & Health status & Health problems & Sickness absence \\
\hline Commuting time & $-0.0061^{* * *}$ & $-0.0022^{* *}$ & $0.0011^{* *}$ & 0.0003 \\
\hline Commuting time squared & $0.0001^{* * *}$ & $2.87 \mathrm{e}-05^{* * *}$ & $-1.41 \mathrm{e}-05^{* *}$ & $-3.39 \mathrm{E}-06$ \\
\hline F-statistic for joint significance & 6.3 & 3.35 & 2.67 & 1.13 \\
\hline (p-value) & 0.0018 & 0.035 & 0.0694 & 0.3245 \\
\hline Individuals & 6330 & 7119 & 7140 & 7140 \\
\hline \multirow[t]{4}{*}{ Observations } & 29869 & 39602 & 42298 & 42328 \\
\hline & \multicolumn{4}{|c|}{ Panel b: No house, job, mode change } \\
\hline & $(1 \mathrm{a})$ & $(2 \mathrm{a})$ & $(3 \mathrm{a})$ & $(4 \mathrm{a})$ \\
\hline & Health satisfaction & Health status & Health problems & Sickness absence \\
\hline Commuting time & $-0.005^{* * *}$ & $-0.003^{* * *}$ & $2.336 \mathrm{e}-04$ & $2.471 \mathrm{e}-04$ \\
\hline Commuting time squared & $5.258 \mathrm{e}-05^{* *}$ & $2.963 \mathrm{e}-05^{* * *}$ & $-2.69 \mathrm{E}-06$ & $-2.20 \mathrm{E}-06$ \\
\hline F-statistic for joint significance & 3.53 & 4.69 & 0.12 & 1.18 \\
\hline (p-value) & 0.0294 & 0.0092 & 0.89 & 0.3064 \\
\hline Individuals & 10083 & 11934 & 12319 & 12322 \\
\hline \multirow[t]{4}{*}{ Observations } & 36013 & 48105 & 51607 & 51641 \\
\hline & \multicolumn{4}{|c|}{ Panel c: Leaving out greater London } \\
\hline & $(1 \mathrm{c})$ & $(2 \mathrm{c})$ & $(3 \mathrm{c})$ & $(4 c)$ \\
\hline & Health satisfaction & Health status & Health problems & Sickness absence \\
\hline Commuting time & $-0.004^{* * *}$ & $-0.002^{* * *}$ & $0.001^{*}$ & $1.731 \mathrm{e}-04$ \\
\hline Commuting time squared & $4.179 \mathrm{e}-05^{* *}$ & $2.187 \mathrm{e}-05^{* *}$ & $-8.068 \mathrm{e}-06^{*}$ & $-1.516 \mathrm{e}-06$ \\
\hline F-statistic for joint significance & 4.62 & 4.66 & 1.58 & 1.04 \\
\hline (p-value) & 0.0099 & 0.0095 & 0.2061 & 0.3521 \\
\hline Individuals & 10990 & 12801 & 13149 & 13151 \\
\hline \multirow[t]{3}{*}{ Observations } & 47303 & 62072 & 66457 & 66503 \\
\hline & Panel d: I & $\begin{array}{l}\text { cluding those } \\
(2 \mathrm{~d})\end{array}$ & $\begin{array}{l}\text { entirely working } \\
(3 d)\end{array}$ & $\begin{array}{l}\text { at home } \\
(4 \mathrm{~d})\end{array}$ \\
\hline & Health satisfaction & Health status & Health problems & Sickness absence \\
\hline Commuting time & $-0.0035^{* * *}$ & $-0.0016^{* * *}$ & $0.0006^{*}$ & $0.0002^{*}$ \\
\hline Commuting time squared & $3.508 \mathrm{e}-05^{* *}$ & $1.478 \mathrm{e}-05^{* *}$ & $-6.648 \mathrm{e}-06^{*}$ & $-1.71 \mathrm{E}-06$ \\
\hline F-statistic for joint significance & 5.32 & 4.48 & 1.56 & 2.21 \\
\hline (p-value) & 0.0049 & 0.0114 & 0.2095 & 0.1096 \\
\hline Individuals & 12909 & 15192 & 15581 & 15585 \\
\hline Observations & 58116 & 77341 & 82805 & 82868 \\
\hline
\end{tabular}

Model: FE OLS

Note: Only the coefficients for the commuting variables are reported. Like in the main tables, the following control variables are included: age, age squared, number of children, relation to household head, marital status, highest education level, region and year dummies. ${ }^{*} \mathrm{p}<0.1 ;{ }^{* *} \mathrm{p}<0.05 ; * * *<0.01$. 
Table 7: Robustness checks for health behavior and health care utilization - sub samples

\begin{tabular}{|c|c|c|c|c|}
\hline & \multicolumn{4}{|c|}{ Panel a: No change in commuting mode } \\
\hline & $(1 \mathrm{a})$ & $(2 \mathrm{a})$ & $(3 a)$ & $(4 a)$ \\
\hline & Regularly sports & BMI & Nr. visits & In-patient \\
\hline Commuting time & -0.001 & 0.0112 & $\begin{array}{l}\text { general practitioner } \\
0.0026^{* *}\end{array}$ & $\begin{array}{l}\text { hospital stay } \\
0.0003\end{array}$ \\
\hline Commuting time squared & $1.54 \mathrm{E}-05$ & -0.0001 & $-3.62 \mathrm{e}-05^{* * *}$ & $-2.84 \mathrm{E}-06$ \\
\hline F-statistic for joint significance & 0.96 & 1.13 & 3.34 & 0.35 \\
\hline (p-value) & 0.3824 & 0.3229 & 0.0353 & 0.7012 \\
\hline Individuals & 6187 & 3151 & 7140 & 7140 \\
\hline \multirow[t]{4}{*}{ Observations } & 17402 & 4408 & 42303 & 42317 \\
\hline & \multicolumn{4}{|c|}{ Panel b: No house, job, mode change } \\
\hline & $(1 \mathrm{~b})$ & $(2 \mathrm{~b})$ & $(3 b)$ & $(4 \mathrm{~b})$ \\
\hline & Regularly sports & BMI & Nr. visits & In-patient \\
\hline Commuting time & -0.001 & -0.002 & $0.003^{* *}$ & $9.884 \mathrm{e}-05$ \\
\hline Commuting time squared & $1.827 \mathrm{e}-05$ & $3.812 \mathrm{e}-05$ & $-3.147 \mathrm{e}-05^{*} \mathrm{~B} 64+\mathrm{B} 26^{*}$ & $-2.581 \mathrm{e}-07$ \\
\hline F-statistic for joint significance & 1.34 & 0.05 & 2.93 & 0.21 \\
\hline (p-value) & 0.2611 & 0.9553 & 0.0532 & 0.81 \\
\hline Individuals & 8626 & 3999 & 12313 & 12319 \\
\hline \multirow[t]{4}{*}{ Observations } & 20786 & 5156 & 51606 & 51628 \\
\hline & \multicolumn{4}{|c|}{ Panel c: Leaving out greater London } \\
\hline & $(1 \mathrm{c})$ & $(2 \mathrm{c})$ & $(3 \mathrm{c})$ & $(4 \mathrm{c})$ \\
\hline & Regularly sports & BMI & $\begin{array}{l}\text { Nr. visits } \\
\text { general practitioner }\end{array}$ & $\begin{array}{l}\text { In-patient } \\
\text { hospital stay }\end{array}$ \\
\hline Commuting time & -0.001 & 0.013 & $0.003^{* * *}$ & $4.746 \mathrm{e}-04^{*}$ \\
\hline Commuting time squared & $1.316 \mathrm{e}-05$ & $-6.934 \mathrm{e}-05$ & $-4.803 \mathrm{e}-05^{* * *}$ & $-5.471 \mathrm{e}-06^{*}$ \\
\hline F-statistic for joint significance & 1.11 & 2.78 & 9.48 & 1.64 \\
\hline (p-value) & 0.328 & 0.0622 & 0.0001 & 0.193 \\
\hline Individuals & 9957 & 4975 & 13143 & 13150 \\
\hline \multirow[t]{4}{*}{ Observations } & 27507 & 6866 & 66458 & 66486 \\
\hline & \multicolumn{4}{|c|}{ Panel d: Including those entirely working at home } \\
\hline & $(1 \mathrm{~d})$ & $(2 \mathrm{~d})$ & $(3 \mathrm{~d})$ & $(4 \mathrm{~d})$ \\
\hline & Regularly sports & BMI & $\begin{array}{l}\text { Nr. visits } \\
\text { general practitioner }\end{array}$ & $\begin{array}{l}\text { In-patient } \\
\text { hospital stay }\end{array}$ \\
\hline Commuting time & -0.001 & $0.0140^{*}$ & $0.0028 * * *$ & 0.0004 \\
\hline Commuting time squared & $1.467 \mathrm{e}-05^{*}$ & $-6.69 \mathrm{E}-05$ & $-3.868 \mathrm{e}-05^{* * *}$ & $-3.79 \mathrm{E}-06$ \\
\hline F-statistic for joint significance & 1.95 & 4.77 & 8.69 & 1.41 \\
\hline (p-value) & 0.1423 & 0.0086 & 0.0002 & 0.2447 \\
\hline Individuals & 11754 & 5873 & 15576 & 15584 \\
\hline Observations & 33812 & 8231 & 82817 & 82848 \\
\hline
\end{tabular}

Model: FE OLS

Note: Only the coefficients for the commuting variables are reported. Like in the main tables, the following control variables are included: age, age squared, number of children, relation to household head, marital status, highest education level, region and year dummies. ${ }^{*} \mathrm{p}<0.1 ;{ }^{* *} \mathrm{p}<0.05 ;{ }^{* * *}<0.01$. 


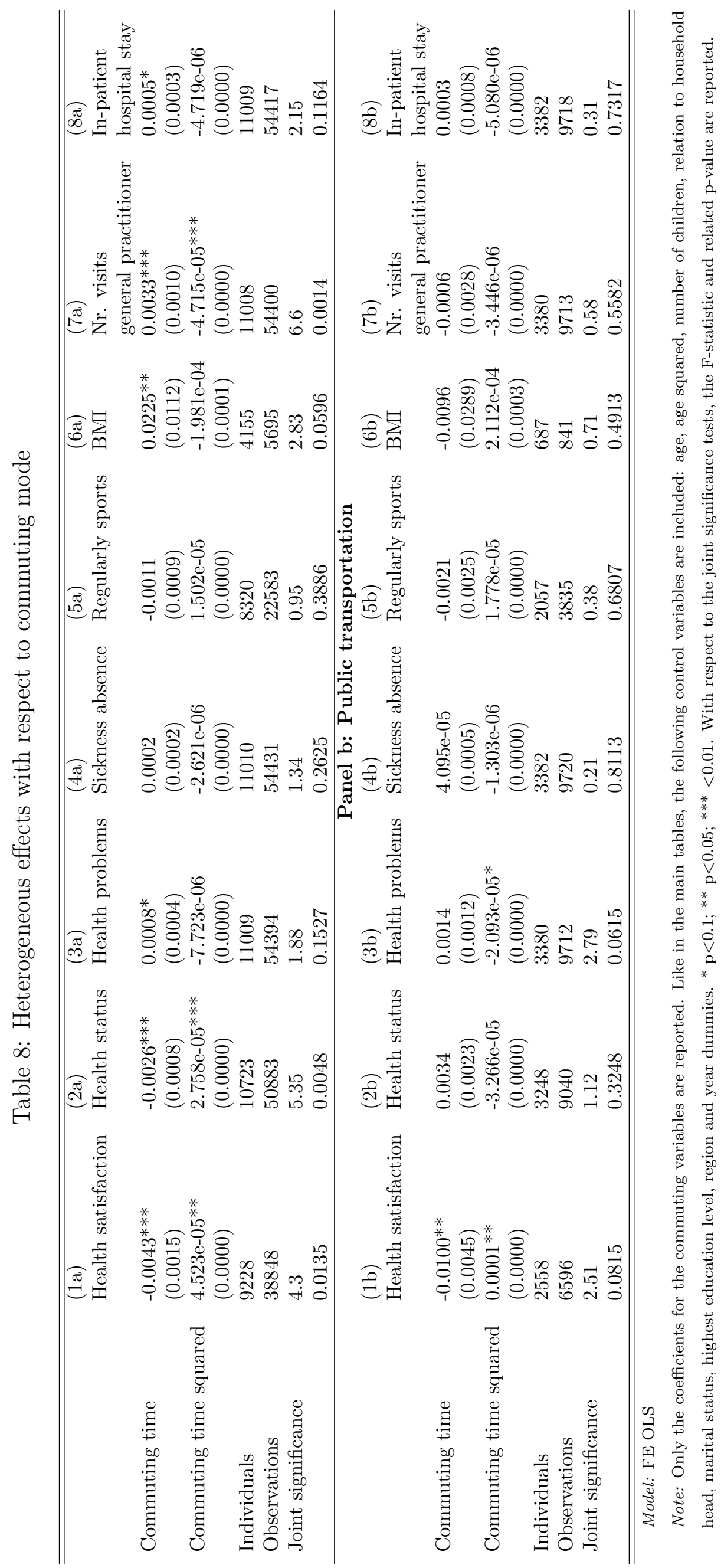




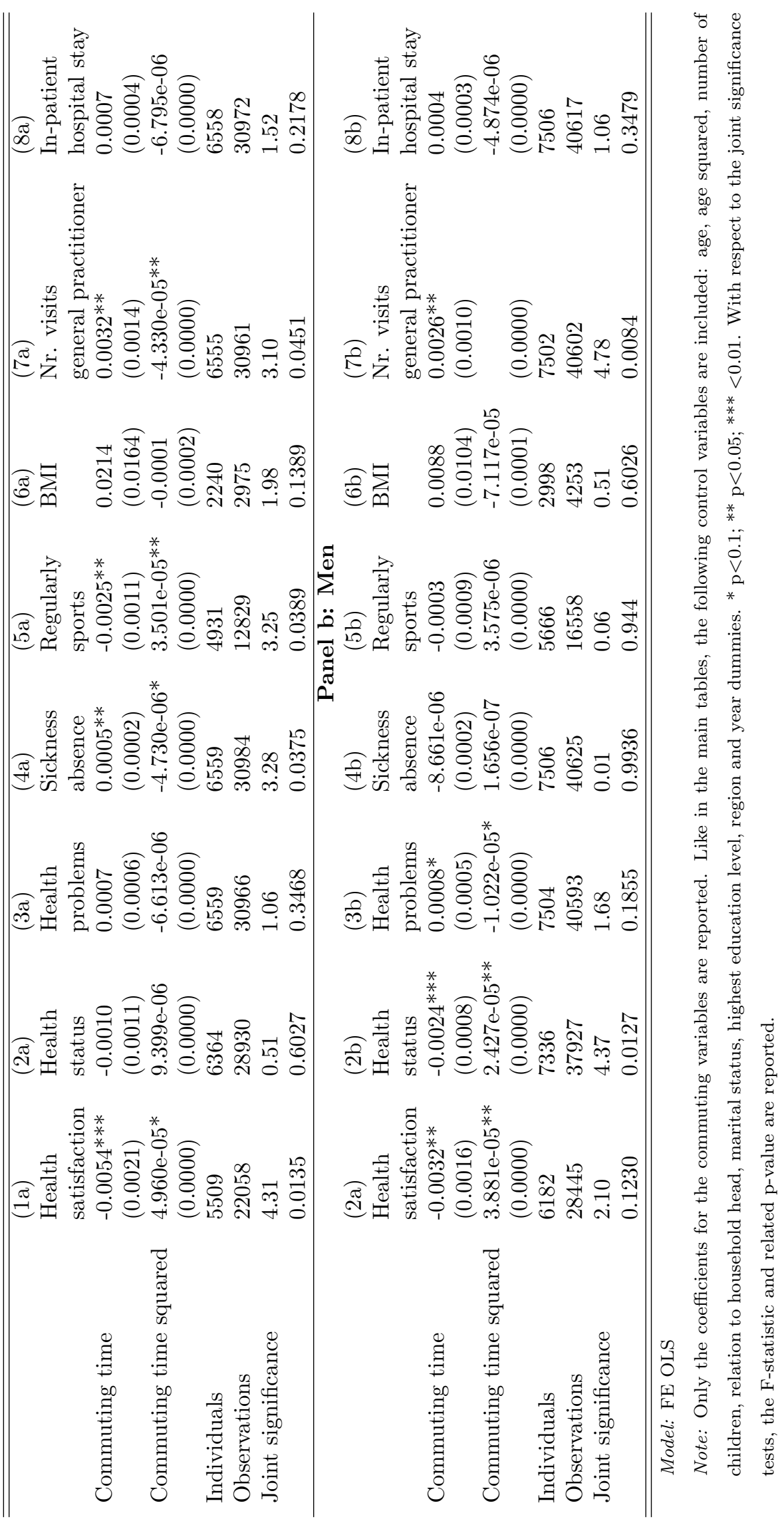

